\title{
Radiology Quiz
}

An 18-month-old female child presented to our OPD with c/o nasal discharge and mild breathing difficulty since birth. There was no history of antenatal, immediate or late postnatal complaints. Child is immunized till date and having normal developmental milestones. She was born full term by cesarean section for CPD with birth weight 3750 gm with Apgar 9 at 1 ' and 5'. No history of respiratory difficulty or cyanosis at birth. The CT scan picture is accompanying. What is the diagnosis?
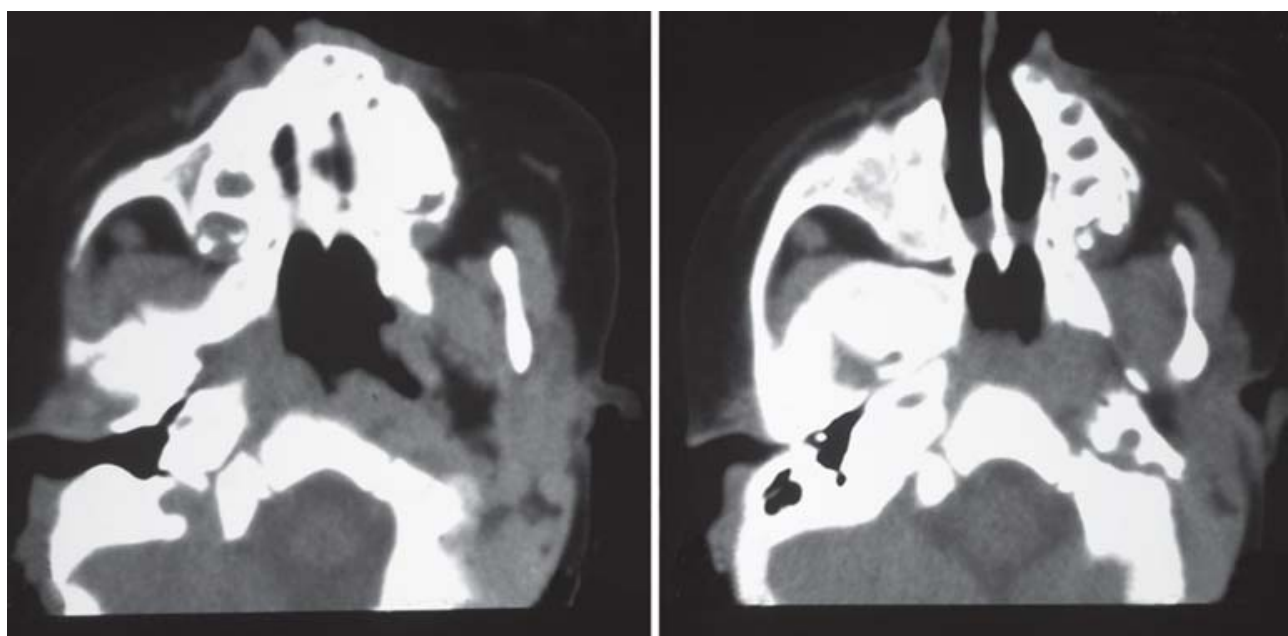

Fig. 1

Send your diagnosis and comments on management to:

Editor-in-Chief

Room No. 25, Block D, Level 2

Faculty Office, Nehru Hospital

Postgraduate Institute of Medical Education and

Research, Chandigarh-160012, India

e-mail: drashokpgi@yahoo.com 